\title{
The Prevalence of Cystic Echinococcosis in Cattle Slaughtered in Sebeta Municipal Abattoir, Central Ethiopia
}

\author{
Biniamin Taha* and Anwar Hassen \\ Haramaya University, College of Veterinary Medicine, Haramaya, Ethiopia
}

Received: June 16, 2018; Published: June 22, 2018

*Corresponding author: Biniamin Taha, Haramaya University, College of Veterinary Medicine, Haramaya, Ethiopia

\begin{abstract}
This paper reports the results of a study conducted from November 2008 to April 2008 at sebeta slaughterhouse. An investigation was carried out to study the prevalence of cystic-echynococcus in cattle's slaughtered in sebeta municipal abattoir. The study revealed that the prevalence that of hydatid cysts is $176.55 \%$ and 74 visceral organs we found harboring one or more hydiatid cysts. The lung was found to be the most commonly affected organ, but Spleen and heart were found to be less commonly affected organ. The numbers of cysts obtained from single lung ranges 1-20. Cyst fertility assessment yielded 65(52\%) sterile, 23(18.4\%) fertile and the rest 37(29.6\%) calcified cysts, $69.6 \%$ of the fertile cysts being confirmed viable cysts and the rate of calcification is higher in the liver than in the lungs, while most fertile cysts were recovered from the lung. This base line information shows the risk of hydatid cyst distribution, and appropriate control measures should be undertaken which includes public awareness education program, revision of meat inspection legislation and a more aggressive effort that should include a reduction of stray dog population.
\end{abstract}

Keywords: Abattoir; Cyst; Echynoccocus; Municipal; Prevalence

\section{Introduction}

Ethiopia despite having enormous livestock population the corresponding productivity remained marginal due to prevalent diseases, malnutrition and managerial constraints. Among the many prevalent livestock diseases parasitism represent a major drawback to development in tropics for that matter it is high in Ethiopia. Nevertheless proper evaluation of public health importance due to various individual parasitic diseases and adequate knowledge of the epidemiology of parasites is lacking which otherwise is of great relevance, where the distribution of the disease determines the type and scope of control measures to be applied Ento [1]. Cestode parasites in animals are important because several of these species are zoonotic causing diseases such as hydatidosis in man and animals. The parasites have indirect life cycles involving definitive hosts, in which the tapeworm stage develops in the small intestines, and intermediate hosts, in which the larval stage develops in the host tissues Thompson [2]. Echinococcosis/ Hydatidosis is a zoonotic diseas caused by tapeworms of the genus Echinococcus that occurs throughout the world and causes considerable economic losses and public health problems in many countries. Taxonomically only four species are accepted and regarded as valid. These are Echinococcus granulosus, Echinococcus multilocularis, Echinococcus oligarthrus and Echinoccus vogeli Thompson [3]. The disease which is caused by E.granulosus has a broad geographical distribution, with highly endemic areas in countries of Africa, Latin America, Australia and Asia Soulsby [4].

The domestic dog as a definitive host of the adult E.granulosus plays the most important role in the spread of infection via contamination of environment creating the domestic life cycle. The maintenance of E.granulosus in wild or feral animals without the involvement of humans or domestic ungulates demonstrates the existence of sylvatic cycles Rausch [2]. Hydatid disease is important from the public health stand point where in man the frequent formation of exogenous daughter cysts further exacerbates the condition. Human behavior plays a significant role in the epidemiology of the hydatidosis and the dynamics of the transmission differs between the dog and its normal intermediate host and human hosts, shwabe [6]. Hydatidosis in human is much more common on the rural areas of Ethiopia were dogs and domestic live in a very close association usually sharing the same accommodation. Man becomes infected by accidental ingestion of onchospheres from contaminated food, water and environments, where as the dog is the commonest final host E.granulosus, which becomes infected by ingestion of, infected offals urquhart et al. [7]. Studies to establish the prevalence of hydatid disease in animals depend mainly on collection of data in slaughter-houses. The prevalence of the disease is domestic food animals show that sheep are the most commonly infected domestic 
intermediate host, through cattle and various other types of livestock are also affected. Infection does not usually result in any sign in livestock soulsby [4].

Echinococcus parasites are difficult to detect in faeces of definitive hosts due to their small size. Diagnosis has been performed by examination of purge contents for the presence of E.granulosus. Poor sensitivity, incomplete purgation, adverse reactions to the drugs in some dogs, and infectivity of the purge material for the personal involved are some of the disadvantages of this method. Recent progress and development of serological diagnostic tests in human hydatid disease has also contributed to the improvement of the detection of the parasite in animals. The more recently developed serological tests for the diagnosis of hydatid diseases are the enzme-linked immunosorbent assay (ELISA), radio immunoassay (RIA) and immunolelctrophoresis (IEP), indirect haemagglutination (IHA) sewell and Brock kesby [8]. The objective of this study was to further investigate the prevalence of hydatid disease in cattle in Sebeta municipal abattoir and to recommend appropriate control measures to the local situation in the area.

\section{Materials and Methods}

\section{Study Area}

This study was conducted in sebeta (sebeta municipal abattoir). Sebeta, the capital city of Alem Genal district in west shoa zonal administration in the Ormiaya regional state. Sebeta is situated $25 \mathrm{~km}$ west of Addis Ababa altitude range from 1500-3000m and total coverage of the area is $103,758 \mathrm{~km}$. this area has a mid sub-tropical weather "weyna Dega" and high land temperature type climate "Dega" accounting respectively $94 \%$ and $6 \%$ of the climate. Mean annual temperature and rainfall ranges between 15to 21oc and 800 to $1199 \mathrm{~mm}$ respectively. Agricultural is the main occupation of the population of the area. The agricultural activities are mainly mixed type with cattle rearing and crop production undertaken side by side. According to the current document of Alem Gena woreda agricultural office report 1996/1997, the total livestock population of this woreda was estimated at 75,193 cattle, 8592 sheep, 9950 goat, 12,337 equine and 39,751 poultry. The major annual crops include teff, wheat, barley, and chick pea. The major type of soil in the area supporting the crops and the flora of the area are $60 \%$ black, $33 \%$ red, $5 \%$ brown, and $2 \%$ Grey soil.

\section{Study Animals}

Cattle mainly of the local breed were inspected the present study. Most of the animals slaughtered were small east African zebu cattle from different origins of wored as, predominantly from western region. Post mortem examination was performed in a total of 376 cattle's. Data such as sex, age group and organ inspected such as hearts, lungs, liver, and kidney and spleens were easily recorded.

\section{Study Design and Sampling Procedure}

Studies to establish the prevalence of hydatid disease in animals depend mainly on collection of data obtained from animals slaughtered in abattoirs. Organs of the abdominal, thoracic and pelvic cavities were examined for the presence of hydatid cysts by observation and palpation with special emphasis being placed on the liver and lungs. The presences of cysts were recorded according to organ distribution. Laboratory examination was carried out on all collected specimens to determine the fertility and viability of the cysts.

\section{Cyst Characterization}

\section{a) Fertility and Viability Study}

The contents of the cyst was aspirated with a syringe to decrease its pressure and collected in a graduated beaker and the rest of the fluid was then added to it and measure its volume and it was allowed to stay on incubator for 30 minutes at 360c to settle the content and then about $10 \mathrm{ml}$ of these sediment was poured to the test tube and centrifuged at $1000 \mathrm{rpm}$ for 3 minutes to separate the contents clearly from the liquid part and the supernatant was discarded, but the sediment with some fluid was left in test tube examination was done under objectives of $40 \%$ magnification for the presence or absence of protscolex. The protoscolex which preset as white dots on the germinal epithelium, or brood capsules or hydatid sands within the suspension cysts was categorized as fertile and further examined for viability was done. A drop of the sediment consisting of the protoscolices was placed in a microscope glass slide, and $1 \%$ eosin solution was added to it and examined according to the description provided by FAO/WHO [9] and McPherson [10] for the amoebid Like peristaltic movement (flame cell activity) with the objective of $40 x$.

\section{Data Analysis}

Basic data entry and handling was done using Ms-excel (Microsoft crop). The aim was to determine the prevalence rate of the disease. Factors such as breed, environment, nutrition, weight, etc. were not considered. The chi-square test was used to compare tabulated percentage. A significant level (p) of less than 0.05 was used as statically significant value.

\section{Results}

\section{Prevalence of Hydatid Cyst}

$66(17.6 \%, n=376)$ cattle were found to harbour hydatid cysts. In this study the lung is found to be the commoniest affected organ, and infection of the lung and liver is secondary, but spleen and heart are the least affected organs. Table 1 represents the distribution of hydatid cyst by organ. The number of cysts range from one in either of the organs to as many as 20 per lung and 2 per liver (Table 2). The total number, organs with one or more Hydiatid cyst was $58(78.38 \%)$ for lungs, $14(18.92 \%)$ for liver, $1(0.8)$ for spleen and $1(08 \%)$ for heart.

Table 1: Distribution of hydatid cyst in different organs.

\begin{tabular}{|c|c|c|c|c|}
\hline $\begin{array}{c}\text { Infected } \\
\text { organ }\end{array}$ & $\mathbf{N}$ & $\mathbf{n}$ & $\begin{array}{c}\text { Infection } \\
\text { rate (\%) }\end{array}$ & $\begin{array}{c}\text { Max. number of } \\
\text { cyst per organ }\end{array}$ \\
\hline Lung & 376 & 58 & 15.4 & 20 \\
\hline Liver & 376 & 14 & 3.72 & 2 \\
\hline Spleen & 376 & 1 & 0.3 & 1 \\
\hline Heart & 376 & 1 & 0.3 & 1 \\
\hline
\end{tabular}

N-Sample size, n-number of infected organs 
Table 2: Total and average no. of cysts per organ examined.

\begin{tabular}{|c|c|c|c|c|}
\hline & Liver & lung & spleen & Heart \\
\hline Highest no of cyst per organ & 2 & 20 & 1 & 1 \\
\hline Total no of cyst & 15 & 108 & 1 & 1 \\
\hline
\end{tabular}

\section{Fertility and Viability}

Out of 125 cysts examined, 65(52.0\%) were sterile, 37(29.6\%) calcified and 23(18.4\%) fertile from which 10 (8.0\%) were motile cysts. The cyst condition by organ involvement was found to be $58(53.70 \%)$ sterile, $19(17.59 \%)$ fertile of which12 (11.11\%) were viable, and $30(27.78 \%)$ were calcified in the lung, and 5 (33.33\%) sterile, $4(26.67 \%)$ fertile of which $1(6.67 \%)$ were viable, and $7(46.67 \%)$ were calcified in the liver, but cysts in spleen and heart were sterile (Table 3). The frequency of occurrence of fertile cysts is higher in the lung than in liver.

Table 3: Descriptions of cyst fertility and viability indifferent organs.

\begin{tabular}{|c|c|c|c|c|c|c|c|c|c|c|c|c|}
\hline \multirow{3}{*}{ Organ } & \multicolumn{6}{|c|}{ Fertile cysts } & \multirow{2}{*}{\multicolumn{2}{|c|}{ Sterile Cysts }} & \multirow{2}{*}{\multicolumn{2}{|c|}{ Calcified cysts }} & \multirow{2}{*}{\multicolumn{2}{|c|}{ Grand total }} \\
\hline & \multicolumn{2}{|c|}{ Motile } & \multicolumn{2}{|c|}{ non motile } & \multicolumn{2}{|c|}{ sub total } & & & & & & \\
\hline & $\mathbf{N}$ & $\%$ & $\mathbf{N}$ & $\%$ & $\mathbf{N}$ & $\%$ & $\mathbf{N}$ & $\%$ & $\mathbf{N}$ & $\%$ & $\mathbf{N}$ & $\%$ \\
\hline Lung & 12 & 11.11 & 7 & 6.48 & 19 & 17.59 & 58 & 53.70 & 30 & 27.78 & 108 & 86.4 \\
\hline Liver & 1 & 6.67 & 3 & 20 & 4 & 26.67 & 5 & 33.33 & 7 & 46.67 & 15 & 12 \\
\hline Spleen & & & & & & & 1 & & & & 1 & 0.8 \\
\hline Heart & & & & & & & 1 & & & & 1 & 0.8 \\
\hline Total & 13 & 10.4 & 10 & 8.0 & 23 & 18.4 & 65 & 52.0 & 37 & 29.6 & 125 & \\
\hline
\end{tabular}

\section{Discussion}

E.granulosus shows considerable geographic variation. Apart from abaiotic variables factors such as differences in culture, social activities and attitude to dogs in different regions contribute to the variation in prevalence rates The fertility rate of hydatidosis is highly important in livestock and public health in different parts of the world, and studies was conducted by different persons in different geographical area, and this shows that the need for strict implementation of control programs SOULSBY [4]. The prevalence rate in this study was obtained to be $17.55 \%$ but the prevalence rate studied in different geographical distribution range from low to very high. Low prevalence rate were reported in Ethiopia from Debra Berhan 7.2\% Tsgaye [11], moderate in Gonder which is 37.7\% Roman [11], Kenya $28.4 \%$ mango et al. [12] and the highest is $54.9 \%$ in Bahir Dar Nebiyou [13]. This variation in prevalence rate may be due to the differences in the origin of animals brought for slaughter and also due to changes in the environment and epidemiological factors, which could affect the rate of transmission of Echinococcosis /hydatidosis. However, further detailed investigation could be made to get concrete information on the dynamics of Echinoccoosis/ Hydatidosis in different area. Varying prevalence rate of echinococcosis has also been reported by various workers in Africa, for example, in the delta $32 \%$ of cattle $58 \%$ of pigs and 42 of goats Arene [14]. This variation in prevalence rate in different countries and region may be attributed mainly to strain differences in E.Granulosus that exist in different geographical situation Arene [14]. This high prevalence may generally be related to the presence of favorable factors for the propagation and maintenance of high-level of infection in the area. These findings are important and are governed by the following events. The age of slaughtered animals is anticipated as one of the reasons contributing to the high prevalence of the disease in the area. Most cattle are slaughtered at their older age when they become exhausted on milk and or calf production or when they have reduced the capacity to work, through which they have a greater chance to be infected with E.granulosus, and hence they were exposed over a longer period of time with an increased possibility of acquiring the infection. Studies conducted in New Zealand also strongly suggest that prevalence is heavily influenced by age. The result from this later study indicated that $3 \%$ of affected cattle were 1-2 years old while $97 \%$ were 5 years and above. Another study in Uganda verified that the prevalence of hydatidosis in calves $7 \%$, cows $52.2 \%$, fattening bullocks $69.7 \%$, bulls and old bullocks $51.2 \%$.

Personal observation also reveals that urban as well as rural dwellers keep at least one dog and they are usually used to guard the livestock outside the farm house at grazing sites and results in contamination of the pasture with their faces, which may contain eggs of E.granulosus, and infection of domestic animals Hubert et al. [15].

The finding records in this study are important and they are governed by the following events:

I. Most cattle are slaughtered at their older age when they became exhausted in milk and /or calf production or when they have reduced capacity to work, through which they have a greater chances to be infected with E.granulosusis.

II. In the rural area, most farmers keep at least one dog and they are usually used to guard the live stock in area outside the farm houses at grazing sites with resultant contamination of the pasture with their faces, which may contain eggs of E.granulosus, and infection of domestic animals.

It has been noted that rates and intensity of infection in ungulates also differ with local method of husbandry Hubert et al. [15].

a) Meat inspection is practiced only at few sites and there is no proper disposal of condemned organs.

b) Home slaughtering is a common practice in the area. People in the area kill domestic animals, particularly sheep and goats, in their backyards, especially during holidays, and meat 
inspection in backyards, especially during holidays, and meat inspection is not practice. Organs to these animals particularly the lungs are frequently used as feed for dogs which leads to intention with fertile protossolices of E.granulosus.

c) There is lack of awareness by the people of the health hazard as well as the economic importances of echinococcosis

d) Dead carcass of domestic animals are usually left unburied allowing scavengers and will carnivores such as dog to feed on them leading to infection with cyst of E.granulosus.

A maximum of 20 cysts were recovered from a single lung and this finding is nearly similar to the findings of Mussie [16] and Fikre [17] and Nebiyou [13] described a maximum of 25, 27 and 28 cysts infecting a single lung respectively. A much superior results were also previously found by Tamene [18], which is 132 cysts per organs. Such variations in cyst abundance on an organ are explained as probably to the spatial distribution and infectivity of Echinooccus eggs Gemmel [19], and to the susceptibility and defensive capabilities of the host Macpherson [9]. In the present study it was found that about $98 \%$ of the case hydatid disease involves the lungs and liver, although lung infection was superior. These findings concords with the observations of other workers such like Nebiyou [13], Roman [11], Tamene [18] and kostei [20] the explanation given is that, these organs are the first capillary sites encountered by the migrating echincoccus oncospehere. In general the liver and lungs are most commonly infected organs both in cattle and sheep. The spleen and kidneys are the least affected organs in cattle and not involved in sheep similar finding were also obtained by various workers and it is indicated that the liver and lungs are most commonly affected organs with hydatid cysts due to the reason that they are the first large capillary fields encountered by the blood bovine oncosphere (Angus, 1978). However development of hydatid cysts occurs occasionally in other organs and tissues when onchospheres escape in to the general systemic circulation urquhart et al. [6]

Evaluation of the condition of hydatid cysts revealed that rates of sterility, fertility and viability vary among different organs. Out of 125 cysts examined 65(52.0\%) were sterile, 37(29.6\%) calcified and $23(18.4 \%)$ fertile of which $10(8.0 \%)$ were viable cysts. These findings may generally imply that most of the cysts on cattle are inferilie and this finding is consistent with the observation of Fikre [18], Nebiyou [14], wubbet (1998), kostei [20], conversely in Britiain up to $90 \%$ of the total cysts from cattle are said to be sterile. On the other hand on some countries like South Africa, Belgium and Rhodesia $96.9 \%, 94.2 \%$ and $86.5 \%$ respectively of the examined hydatid cysts were sterile. The variation in fertility rates in different geographical zones of the globe could be allocated to strain differences of E.granulosus strains of the parasites and host can modify the infective of the parasite. From the fertility study, the percentage of fertile cysts was found to be lower in cattle. In Britain up to $80 \%$ of the total cysts from cattle are said to be sterile. Conversely, in some countries like South Africa, Belgium, and Zimbabwe, 96.9\%, 94.2and $86.5 \%$ respectively, of the uncalcifed cysts were fertile Arene [14].
Fikre [17] have, got higher fertility rate of hydatid cysts in sheep and goats than in cattle. It has been noted that species vary in their suitability as intermediate hosts, and hydatid cysts found in sheep are usually fertile where as those in cattle are usually sterile. This variation could be attributed to strain differences in E.granulosus Soulsby [4] in that strains may differ in traits such as host preferences, development rate, infectivity pathogenesis, anitigenicity and drug resistance. Moreover, it has been indicated that ovine strain of E.granulosus imposes tremendous effect on the health hazard in respect to human population and the presences of fertile cysts on cattle of an apparent ovine strain may constitute an additional public health problem. The fertility rate was higher among the cysts of lungs than the liver. This is in agreement with the results of other workers and it has been stated that the relatively softer consistency of lung allows easier development of the pre-sorted cyst and the frowsy of legated cysts may show a tendency to increase worth advanced lost, that may be related with reduced immunological compatibility of the hosts at their old age of infection. Hubert et al. [15]. The percentage of calcified cysts is found to be higher in the liver than in the lungs. This may be associated with the relatively higher reticuloendothelial cell land abundant connective tissue reaction of the oran Gemmel [19] which encapsulates the cysts within a fibrous wall up to 13 mmthick Gracey [21].

The complete absences of reported human hydatid cases from sebeta clinics may not necessarily lead to the conclusion that the study region is free of these diseases. The lack of modern diagnostic facilities, clinical similarities with other diseases and its asymptomatic appearance and extended incubation period added to the inability to afford medical treatment by the most vulnerable section of the society could have contributed to the obtained result further detailed study in this regard in recommended.1. There is obvious economic loss due to bovine hydatdosis at sebeta municipal abattoir from offal condemnation and carcass weight loss. It is, therefore, concluded that owning to the presences of socioeconomic conditions that favorable for the propagation and maintenances of high level infection in the study area and considering the incalculable indirect loss from it, hydatidosis is one of the most economically important disease in western shows and its surroundings, warranting serious attention for its control and preservation.

\section{Conclusion and Recommendation}

Echinococccosis/ hydatidosis are a disease of considerable importance both from public health and economic view points. The prevalence of the disease in cattle and the corresponding economic losses in cattle slaughtered at sebeta municipal abattoir are judged as considerable by all standards. In view of the results obtained from the present study and the prevailing socioeconomic realities in sebeta and its surrounding the following recommendation are forwarded, while at the same time admitting the limitation faced due to the scope other present study.

i. Education of the people both in formal and in formal ways concerning the public health hazard as well as the economic importance of echinococcosis. 
ii. Imposing legislative measure will put an end to back yard and roadside slaughter practices, construction of slaughter houses with adequate killing facilities and conducting an obligatory meat inspection services and institution of subsidiary operation by the government.

iii. The existing slaughter house should be properly fenced and access to offal by carnivore must be denided. That local slaughter houses should also have offal disposal pits which are deep and dop proof. In the meat factory effective supervision of disposal of condemned offlals appears necessary.

iv. The dog population should be reduced though elimination of stray dogs, especially with the collaboration of the rabies control scheme

v. Further detailed investigation of the basic local epidemiological factors governing the dissemination of echinocoscosis must be carried out.

\section{Acknowledgement}

We owe a great deal to staff members of National Animal Health Diagnostic and Investigation Center (NAHDIC) and Sebeta municipal abattoir meat inspector Mr. Abebe for his reliable support in post mortem examination and to Dr. Desalegn Lidetu (NAHDIC office member) for his valuable support in laboratory examination of the cysts.

\section{References}

1. Ento S (2005) Ticks in Ethiopia.

2. Raush RL (1986) The biology of Echinococcus and hydatid disease. In: RCA Thompson (Eds.), George Allen and Unwin, London, UK, p. 44-80.

3. Thompson RCA (1986) The biology and systematic of Echinococcus. Academic Press, London.

4. Soulsby EJL (1982) Helminths, arthropods and protozos of domesticated animals. $\left(7^{\text {th }}\right.$ edn), bailliere Tindall, London.

5. Schwabe CW (1984) veterinary medicine and human health ( $3^{\text {rd }}$ edn), Williams and wilkins Baltimore, USA, pp. 215-498.

6. Urquhart GM, Armour J, Duncan JL, Dunn AM, Jennings FW (1996) Veterinary parasitolgy. Scotland, Black well science ltd, USA, pp. 181186.

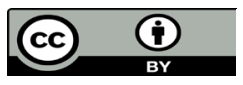

This work is licensed under Creative Commons Attribution 4.0 License

Submission Link: https://biomedres.us/submit-manuscript.php
7. Sewell M, Brocklesby D (2002) Hand book on Animal disease in the tropics ( $\left.4^{\text {th }} e d n\right)$. Billiard Tindall, Great Britain, Uk, pp 117-119.

8. FAO/WHO (1982) Guide lines for Echonococcosis surveillance prevention and control. FAO 29: 147.

9. McPherson LNL (1985) Epidemiolgy of hydatid disease in Kenya. A study of the domestic Intermediate hosts on Masailand. Tran Roy Soc Trop Med and Hyg 79(2): 209-217.

10. Tsegaye M (1995) Epidemiology of bovine fasciolosis and hydatidosis in Debre Brihan, DVM Thesis AAU, FVM, Debre Zei. Ethiopia.

11. Roman T (1987) study on economic significance of bovine Fascioliasis and hdatidosis at Gondar abattoir, DVM Thesis, AAU, FVM, Debre Zeit, Ethiopia.

12. Mango LK, Esmmal D, Kcriuki D (1974) Prevalence of selected common parasitic helminthes of livestock in Kenya. Vet, keb 94: 432-435.

13. Nebiyo G (1990) Study of Hydatidosis/Echinococosis on cattle slaughtered at Bahir Dar municipal slaughterhouse, DVM Thesis, AAU, FVM, Debre Zeit, Ethiopia.

14. Arene FOI (1958) prevalence of hydatidosis on domestic livestock in the Niger Delta. Tropical animalhealth and production 17(1): 3-5.

15. Hubert WT, Culloch WF, Schnurrenberger AA (1975) Diseases transmitted from animals to man ( $6^{\text {th }}$ edn) Charles Thomas publisher, USA.

16. Mussie T (1995) An assessment trial on prevalene and Economic importance of hydatidosis at bahir Dar slaughterhouse, DVM Thesis, AAU, FVM, Debre Zeit, Ethiopia.

17. Fikre L (1994) An Assessment trial of the prevalence, Economic and public heatlth importance of hydatidosis in Konso (south Ethiopia), DVM Thesis Addis Ababa University, FVM, Debre Zeit, Ethiopia.

18. Tamene M (1986) A preliminary study of Echinococcosis/ Hydatidosis in livestock (cattlesheep andgoat) in Gondar administrative region. DVM Thesis AAU, FVM, Debre-zeit, Ethiopia.

19. Gemmel MA (1979) Hydatidosiss control a global review. Aus Vet J 55: 118-125.

20. Kostei PK (2005) Co-operative study on prevalence and strain differentiation of E.granulosus in Ethiopia.

21. Gracey JF (1986) Meat Hygiene, ( $8^{\text {th }}$ edn), Bailliere, Tindall, London., Great Britain, pp. 517.

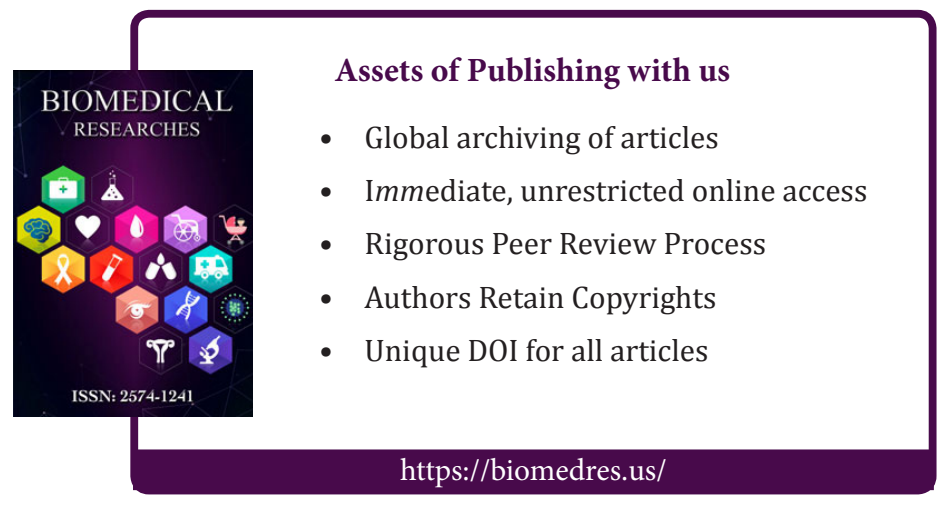

